\title{
A MPB sob suspeita: a censura musical vista pela ótica dos serviços de vigilância política (1968-1981)
}

Marcos Napolitano

Departamento de História - UFPR

\section{RESUMO}

A partir de fontes pesquisadas junto às coleções documentais da polícia política ligadas ao regime militar brasileiro, podemos vislumbrar não apenas o impacto do autoritarismo na cena musical brasileira, entre 1968 e 1981, mas também a lógica da repressão e do controle do Estado autoritário sobre os músicos. Nesse período, o controle da circulação das canções e da realização de shows com cantores esquerdistas (ou simpatizantes) marcou a atuação dos órgãos de censura e repressão, voltados principalmente (mas não apenas) contra o gênero MPB. Neste trabalho, analisaremos o imaginário produzido pelos agentes repressores e a "lógica da produção da suspeita” sobre a MPB.

Palavras-chave: Brasil: Música e Política; Brasil: regime militar; Resistência democrática.

\section{ABSTRACT}

Analyzing the sources produced between 1968 and 1981 by the Brazilian political police and intelligence services, we could observe not only the impact of authoritarian order upon the musical scene, but also the logic of repression and control which ruled the State policy. In this period, the control of social circulations of opposite songs, focused mainly the genre known as MPB (Brazilian Popular Music), became part of the musical scene. In this article, we analyze the strategies and symbolic frame of the "making of suspicion" upon singers and composers, by repressive State services. Keywords: Brazil: music and politics; Brazil: military regime; Democratic resistance.

\section{A PRODUÇãO DO SILÊNCIO E DA SUSPEITA}

Para quem escreviam os espiões da ditadura militar? Esta é a questão que reverbera quando são analisados os relatórios, dossiês, prontuários e outros gêneros de escrita burocrática produzidos pelos serviços de vigilância e repressão, entre os quais destacava-se o DOPS. ${ }^{1} \mathrm{O}$ campo social da vigilância e 
do controle, dentro da lógica da segurança nacional implantada pelo golpe militar de 1964, era enorme: entidades da sociedade civil, espaços de sociabilidade e cultura, atuação pública de personalidades críticas, todo o tecido social e os espaços públicos eram virtualmente vigiados.

O regime militar brasileiro, como de resto outras ditaduras latino-americanas, concentrou-se em vigiar e controlar o espaço público, regido por uma lógica de desmobilização política da sociedade como garantia da "paz social". Neste sentido, esses regimes poderiam ser caracterizados como autoritários, pois sua atuação voltava-se para o controle e esvaziamento político do espaço público, preservando certas formas de liberdade individual privada.

Se a violência policial, legal e ilegal, era sistemática e utilizada contra inimigos e críticos do regime em casos extremos e em situações nas quais os generais no poder sentiam-se particularmente ameaçados, a vigilância sobre a sociedade civil era constante. A obsessão pela vigilância como forma de prevenir a atuação "subversiva", sobretudo naquilo que os manuais da Doutrina de Segurança Nacional chamavam de "propaganda subversiva" e "guerra psicológica contra as instituições democráticas e cristãs", acabava por gerar uma lógica da suspeita ou "ethos persecutório".' Os milhares de agentes envolvidos, funcionários públicos ou delatores cooptados, eram regidos por essa lógica e, ao incorporá-la, acabavam produzindo um fenômeno que é típico de regimes autoritários e totalitários: mais importante do que a produção da informação em si, era a produção da suspeita.

Dentro dessa lógica de "produção da suspeita" ${ }^{3}$ produzida pelos informantes, a "comunidade de informações" não apenas alertava o governo e os serviços de repressão direta para situações concretas de contestação ao regime, mas, através da sua interminável escritura, elaborava perfis, potencializava situações, criava conspirações que, independentemente de qualquer coerência ou plausibilidade, acabavam por justificar a própria existência desses serviços. Mobilizava um conjunto de estratégias discursivas e técnicas de registro (se quisermos manter os termos foucaultianos) para criar uma representação do inimigo interno que poderia estar oculto no território da política, e, principalmente, da cultura. Os espaços, instituições e personalidades ligados à cultura (artes, educação, jornalismo) eram particularmente vigiados pela "comunidade". Num dos manuais de vigilância anticomunista produzidos pelo regime militar lê-se, a título de instrução para o cidadão desprevenido:

Aprender a ler jornais, ouvir rádio e assistir TV com certa malícia. Aprender a captar mensagens indiretas e intenções ocultas em tudo o que você vê e ouve. 
Não vá se divertir muito com o jogo daqueles que pensam que são mais inteligentes do que você e estão tentando fazer você de bobo com um simples jogo de palavras. ${ }^{4}$

Portanto, a esfera da cultura era vista com suspeição a priori, meio onde os "comunistas" e "subversivos" estariam particularmente infiltrados, procurando confundir o cidadão "inocente útil". Dentro dessa esfera, o campo musical destacava-se como alvo da vigilância, sobretudo os artistas e eventos ligados à MPB (Música Popular Brasileira), sigla que desde meados dos anos 60 congregava a música de matriz nacional-popular (ampliada a partir de 1968, na direção de outras matrizes culturais, como o pop), declaradamente crítica ao regime militar. A capacidade de aglutinação de pessoas em torno dos eventos musicais era uma das preocupações constantes dos agentes da repressão.

Através das fontes coletadas junto às coleções do DOPS, nos Arquivos Públicos do Rio de Janeiro e em São Paulo é possível ter uma idéia das estratégias, do imaginário e das representações simbólicas que regiam o olhar e a produção escrita dos agentes da repressão, dentro da estratégia da produção da suspeita. Grosso modo, eles eram norteados por uma mistura de valores ultramoralistas, antidemocráticos e anticomunistas. Na diversidade de gêneros de escrita da burocracia repressiva, percebe-se uma certa incoerência e descompromisso com a verdade, dada a necessidade de superdimensionar qualquer atitude que pudesse ser considerada suspeita.

As táticas da produção da suspeita sobre os artistas obedeciam a uma lógica perversa, apesar da aparente improvisação e falta de critérios. As principais peças acusatórias notadas nos documentos foram as seguintes, em grau de suspeição decrescente: a) participação em eventos patrocinados pelo movimento estudantil; b) participação em eventos ligados a campanhas ou entidades da oposição civil; c) participação no "movimento da MPB" e nos "festivais dos anos 60"; d) conteúdo das obras e declarações dos artistas à imprensa (cujas matérias eram anexadas aos informes, relatórios e prontuários, como provas de acusação); e) ligação direta com algum "subversivo" notoriamente qualificado como tal pela "comunidade de informações". Neste sentido, Chico Buarque de Hollanda era dos mais citados; f) citação do nome do artista em algum depoimento ou interrogatório de presos políticos (bastava o depoente dizer que gostava do cantor ou que suas músicas eram ouvidas nos "aparelhos" clandestinos). Todos esses fragmentos, espalhados em centenas ou mesmo milhares de documentos, eram eventualmente reunidos na forma de peças acusa- 
tórias, os chamados "prontuários", sínteses de informes (anotações dos informantes e coleta de "material subversivo" feita pelos agentes), fichas pessoais e informações reservadas (textos já processados e sintetizados).

Por exemplo, a partir de um balanço sobre a vida cultural no Brasil, publicado pela revista Visão (ano 5, n.44) no final de 1974, o relator do DOPS procurava incriminar não apenas os artistas citados (Oduvaldo Vianna Filho e Ferreira Gullar), mas também os jornalistas e editores da revista. A ligação com o setor estudantil, foco de recrutamento da luta armada de esquerda recentemente derrotada, era a principal peça acusatória que recaía sobre os suspeitos:

Deixando o setor cultural [sic], voltam-se para a música, onde ainda calcados no atos do ex-CPC da ex-UNE, desenvolveram atividades junto às universidades, buscando em universitários os porta-vozes das palavras de ordem contestatória.

O agente-relator procura enfatizar as "relações perigosas" entre os jornalistas e os artistas, no caso, dois militantes assumidos do Partido Comunista Brasileiro e, ao mesmo tempo, denunciar as táticas de "guerra psicológica" contra o regime:

Trata-se, realmente, de um relato apologístico dos feitos de elementos reconhecidamente comunistas e nacionalistas, contrários ao regime instaurado a 31/03/1964. Em toda a narrativa, os editores usam expressões depreciativas, com referência ao governo revolucionário fazendo crer aos leitores encontrar-se o país sob o regime do terror. ${ }^{5}$

O dado bruto do trabalho persecutório e da produção da suspeita era o "informe" (notícias, dados, notas de esclarecimento). A partir do "informe" produzia-se a "informação", documento que já continha certo nível de processamento dos dados brutos coletados, apontando para possíveis ações repressivas mais diretas. ${ }^{6}$ Se os informes e as informações tinham a função de esquadrinhar as atividades potencialmente ou declaradamente "subversivas" dos artistas ou do seu público, havia um conjunto de documentos voltados para a vigilância e o controle dos indivíduos considerados "suspeitos". Basicamente, compunham-se de quatro tipos: ${ }^{7}$ o levantamento de dados biográficos; as fichas-conceito (levantamento da atuação pública e profissional); o prontuário (histórico das atividades registradas do "suspeito") e o juízo-sin- 
tético (espécie de parecer do agente sobre o indivíduo). Esse conjunto de documentos tinha a clara função de peças acusatórias, em eventuais processos ou punições mais direcionadas, prontos para serem acionados a qualquer momento. Em muitos casos, os informes e informações não eram monopolizados por um único órgão de informação, sendo freqüente o intercâmbio de documentos entre os diversos órgãos do sistema.

Todas as ações e declarações que se chocassem contra a moral dominante, a ordem política vigente, ou que escapassem aos padrões de comportamento da moral conservadora, eram vistos como suspeitos. No caso da música, o conteúdo das letras cantadas, a performance e as eventuais declarações que o artista proferisse durante os seus shows, também poderiam agravar o seu "perfil suspeito", ganhando destaque nas anotações dos agentes da repressão política. Além de registrar palavras e atitudes, os textos revelam as inferências dos agentes, no sentido de apontar a existência de uma conspiração perpétua, orquestrada por grupos políticos "subversivos" que se serviam do campo da cultura para iniciar a "guerra psicológica”. Uma simples observação, contida num registro sobre as atividades do suspeito, poderia tornar-se mais destacada em futuros relatórios produzidos pelos organismos, numa técnica de reiteração crescente que agravava o grau de suspeição sobre os vigiados. ${ }^{8}$

Curiosamente, os agentes politizavam muito mais o campo da MPB, aumentando o grau de suas efetivas e orgânicas articulações político-partidárias. Por exemplo, lê-se num informe produzido em 1968 que o campo da música popular ${ }^{9}$

vem se constituindo num dos principais meios de cisão psicológica sobre o público, desenvolvida por um grupo de cantores e compositores de orientação filo-comunista, atuando em franca atividade nos meios culturais. Dentre os principais agentes desse grupo se destacam: FRANCISCO BUARQUE DE HOLANDA, EDU LOBO, NARA LEÃO, GERALDO VANDRÉ, GILBERTO GIL, CAETANO VELOSO, MARILIA MEDALHA, VINÍCIUS DE MORAES, SIDNEY MULLER, GUTEMBERG, "MILTONS" [sic] NASCIMENTO, etc.

Afora os Festivais das canções, onde "predominam" [ sic] a música denominada jovem, transformando-se em clima do não conformismo, da crítica e agressividade às instituições, para dominar o público mostrando-lhe sua coragem, sua arte sem condicionamentos, indiferentes aos gritos dos "reacionários". 
A VIGILÂNCIA DO REGIME MILITAR SOBRE

O MEIO MUSICAL: UMA CRONOLOGIA

O leque de atuação dos agentes dos órgãos de repressão junto ao meio musical vai de 1967 a 1982, conforme as coleções do DOPS disponíveis no Arquivo Público de São Paulo e do Rio de Janeiro. Podemos notar algumas dinâmicas diferenciadas dentro dessa cronologia mais ampla. Entre 1967 e 1968 já se configurara o campo da $\mathrm{MPB}$, para o que concorreu o sucesso dos festivais da canção dos anos 60; concomitantemente, houve o recrudescimento da "questão estudantil”, o que levou a repressão a destacar o papel da música como "propaganda subversiva" e "guerra psicológica”. O principal suspeito de então, aglutinador dos opositores, era Geraldo Vandré, surgindo muitas referências a Nara Leão, Edu Lobo, Caetano Veloso e Gilberto Gil, entre outros.

A partir de 1971, os shows do chamado "Circuito Universitário" ${ }^{10}$ passam a ocupar a maior parte dos informes e relatórios. O inimigo número 1 do regime passou a ser Chico Buarque, secundado por Caetano Veloso, Gilberto Gil, Milton Nascimento, Gonzaguinha e Ivan Lins. Com o exílio de Vandré e sua desagregação enquanto persona pública do meio musical politizado, aliado às novas posturas de Chico Buarque, este passa a ser destacado como o centro aglutinador da oposição musical de esquerda, sendo freqüente nas fichas e prontuários aparecer a expressão "pessoa ligada a Chico Buarque de Hollanda”, como se essa relação, por si, aumentasse o grau de suspeição.

Depois de 1978, a participação dos compositores e cantores na Campanha da Anistia ${ }^{11}$ e nos eventos do movimento operário ${ }^{12}$ se agregou ao mapa da suspeição que recaía sobre eles. Elis Regina, já citada nos primeiros relatórios e informações, começa a aparecer com mais freqüência por ter gravado o "hino da Anistia” (a canção O bêbado e a equilibrista, de João Bosco e Aldir Blanc).

Os documentos produzidos pela vigilância dos serviços de informação e repressão do regime nos permitem, indiretamente, mapear a circulação social da MPB, ao menos enquanto experiência sociocultural presencial e direta. ${ }^{13}$ Num primeiro momento, o foco de atenção recai sobre a platéia dos festivais da canção abrigados nas televisões. Em seguida, passa a abranger o circuito universitário da primeira metade dos anos 70, realizado nos campi e nos ginásios das médias cidades do interior.

No início da década de 1970, sobretudo entre 1971 e 1974, a vigilância sobre a MPB estava ligada, intimamente, à vigilância sobre o movimento estudantil. É de supor que este determinava os termos da vigilância e da suspeita 
sobre aquela. Qualquer movimento de artistas ligados à MPB junto ao público jovem e estudantil deveria ser objeto de atenção redobrada e preventiva. Em 1973, o Centro de Informações do Exército em Brasília enviou uma solicitação formal ao DOPS ${ }^{14}$ do Rio de Janeiro para "acompanhar o comportamento de estudantes e artistas no show de Vinícius de Morais O POETA, A VOZ E O VIOLÃO, no Rio de Janeiro (Com Vinícius, Clara Nunes e Toquinho - além de participações especiais de Chico Buarque, Maria Bethânia e outros)".

O informante, entretanto, tranqüiliza os seus superiores quanto ao citado show afirmando que "a platéia é formada por pessoas maduras e que apenas nos fins de semana há predominância dos 'elementos jovens'. Também não há contato entre espectadores e artistas, uma vez que no auditório não há acesso ao palco, não havendo possibilidade de diálogo".

Na segunda metade da década, os agentes da repressão destacam os espetáculos de massa ligados às campanhas políticas e às entidades de oposição, com destaque para o Comitê Brasileiro de Anistia, a Sociedade Brasileira para o Progresso da Ciência e o Comitê Brasil Democrático. Finalmente, o movimento operário, na virada da década de 1970 para a de 80, passou a ser a grande preocupação da "comunidade de informações", cuja ação se viu enfraquecida após o atentado frustrado do Riocentro, que seria perpetrado, justamente, contra um show de MPB no dia $1^{\circ}$ de maio de 1981.

A produção da suspeita se fazia pela vigilância a eventos, personalidades e espaços sociais considerados, em si e por si, "subversivos" e pela vigilância à atuação pública ou às ligações partidárias de personalidades do meio artísticomusical. Além de certos espaços sociais serem considerados suspeitos, qualquer atitude poderia ser qualificada como subversiva, fosse ela de ordem políticoideológica ou comportamental. As inferências dos agentes da repressão, porém, não eram aleatórias, na medida em que se pautavam pelo imaginário que aglutinava, muitas vezes sem a mínima plausibilidade, o medo à desordem política e social com a dissolução dos laços morais e familiares, pautados por um pensamento ultraconservador. Para a lógica da repressão as duas coisas andavam pari passue, nesse sentido, compreendemos por que tanto Chico Buarque quanto Caetano Veloso, dois artistas com posições ideológicas e graus de engajamento político distintos, eram vistos como ameaças à ordem vigente. 


\section{A VIGILÂNCIA SOBRE OS EVENTOS MUSICAIS}

A explosão dos festivais da canção, sobretudo os festivais da TV Record de São Paulo, a partir de 1966, coincidiu com o crescimento da agitação estudantil. A "setembrada" estudantil daquele ano, quando os estudantes saíram às ruas para protestar contra o regime, foi seguida pela "outubrada" musical, culminando no frenesi provocado pelas apresentações de A banda e Dispara$d a$, esta última consolidando a vocação de sucesso comercial da canção engajada brasileira. No ano seguinte, os serviços de vigilância e repressão apontavam, em Informação produzida pelo II Exército de São Paulo, ${ }^{15}$ a TV Record e a Rádio Panamericana (atual Jovem Pan) como "foco" de "ação psicológica sobre o público, desenvolvida por um grupo de cantores e compositores de orientação filo-comunista, atualmente em franca atividade nos meios culturais". O relator dá nome aos "agentes do grupo": Ellis [sic] Regina, Gilberto Gil, Nara Leão, Chico Buarque, Edu Lobo e Geraldo Vandré. O restante do documento ${ }^{16}$ é uma mistura de fragmentos de delação, registros de eventos públicos e considerandos do agente:

2. A ação se desenvolve através da chamada "música de protesto", numa propaganda sub-liminar muito bem conduzida. Entre as músicas mais difundidas por aquelas emissoras, destaca-se AROEIRA, de Geraldo Vandré, cujo texto emprega ostensivamente a revolta e a subversão.

3. Geraldo Vandré, que é também fiscal da SUNAB, é tido como comunista atuante. Consta que seu pai, médico em João Pessoa, é um dos chefes comunistas do Estado da Paraíba.

4. No dia 5 de julho teve início o programa “DIA DA M.P.B.” desenvolvido pelo referido grupo. O programa procura interessar particularmente aos estudantes, alguns, portando cartazes com inscrições também de protesto, outros com frases MPPD (Movimento Popular Pela Democracia). O programa desse dia foi dirigido pela cantora Elis Regina, o próximo, dia 12/07, será dirigido por Geraldo Vandré.

Os espetáculos organizados pelos centros acadêmicos e diretórios estudantis eram particularmente vigiados. A respeito de um espetáculo de MPB promovido em 1972 pelos universitários do curso de Direito e de Engenharia da PUC-RJ, o agente escreveu: ${ }^{17}$ 
O show teve como animador o universitário de direito Arlindo*, que apresentou Chico Buarque, Sérgio Ricardo, MPB-4 e outros. O apresentador mencionado ... é elemento ativo no meio estudantil, inclusive freqüentando reuniões no DCE, não se omitiu fazendo diversas insinuações em tom de blague, inclusive fez solicitação em nome dos colegas universitários da PUC para que todos lutassem para que fossem soltos os elementos detidos recentemente na PUC...

Os serviços de informação apontavam todas as situações que pudessem ser consideradas potencialmente subversivas, ainda mais quando envolviam artistas reconhecidamente engajados e de esquerda. Durante o mesmo show, o agente destaca a performance de Sérgio Ricardo: ${ }^{18}$

Outro a fazer insinuações durante a sua apresentação, sempre com comicidade e picardia, mas de modo bem discreto foi o cantor Sérgio Ricardo, que inclusive cantou certa canção não inserida na programação distribuída que fixava as primeiras letras do alfabeto, frisando a letra $\mathrm{C}$, perigosa, que tomassem cuidado por ser a inicial de COMUNISTA.

Os relatórios de informação utilizavam-se de agentes infiltrados que esquadrinhavam o ambiente e arrolavam todas as formas de ação e palavrasde-ordem que pudessem caracterizar um clima de comício político. Por ocasião do I Festival Universitário de Niterói, em março de 1972, registrou-se o seguinte: ${ }^{19}$

1. No palco via-se uma faixa que dizia "AMANHÃ SERÁ OUTRO DIA" e os universitários cantavam o samba "APESAR DE VOCÊ AMANHÃ HÁ DE SER OUTRO DIA", de Chico Buarque.

2. O conjunto MPB-4, empregando a melodia do hino das "Olimpíadas dente de leite", fizeram $[s i c]$ propaganda de um "produto que deixava o 'dedo duro' e que podia enfiar o dedo na....”.

3. Leram um artigo sobre a prisão de universitários da PUC e correram uma faixa onde se lia "SECUNDARISTAS SOLIDÁRIOS COM OS UNIVERSITÁRIOS”.

4. Ao final do "show" apresentaram uma faixa, que dizia: PELA CULTURA, CONTRA A CENSURA.

5. Uma camionete da Agência Fluminense de Informações, órgão do Palácio do 
Governo dirigida por um tal de Dr. Flávio, percorreu a cidade, fazendo propaganda do festival.

6. Distribuíram as folhas anexas a todos que compareceram.

7. Distribuíram outra folha mimeografada, somente a estudantes com carteiras.

Freqüentemente, dentro da estratégia da "reiteração" da suspeita com base em eventos passados, os documentos produzidos pela repressão aludem às relações e a outros contextos que pudessem potencializar a suspeita. Ao anotar suas impressões sobre um show de Vinícius, Toquinho e Marilia Medaglia, parte do "circuito universitário" de 1972, o agente destaca que Marilia Medaglia era "a segunda esposa de ... Isaias Almeida Medalha, de posição ideológica contrária ao regime” e adverte:

Segundo informe ... os epigrafados, com outros integrantes do movimento denominado 'Música popular brasileira' estão visitando universidades da capital e interior, alertando-se para uma análise estimativa sobre as intenções a que se propõem, recordando-se atividade semelhante no ano de $1967 \mathrm{com}$ a fase de aglutinação do movimento estudantil iniciado com programa congênere de Geraldo Vandré, seu idealizador.

Neste caso, percebemos o funcionamento de uma memória própria da burocracia repressiva ao recordar-se o contexto de 1967, ano de preparação da luta armada no meio intelectual e estudantil. Os termos do documento sugerem uma espécie de "peregrinação política" dos artistas de esquerda em várias universidades, quando, na verdade, o "circuito universitário" era um circuito comercial de baixo custo de produção e uma opção de trabalho numa época de censura dos meios de comunicação e cerceamento dos músicos ligados à $\mathrm{MPB} \cdot{ }^{20} \mathrm{~A}$ referência à Geraldo Vandré, na época já uma lenda viva da música brasileira, porém desaparecido da cena musical, procura dar um tom ainda mais grave às advertências do agente. Contrastando com esse tom "conspirativo", o texto ${ }^{21}$ reconhece que "durante o espetáculo não foram anotadas aleivosias ou referências ofensivas às instituições”.

No início da década de 1970, o cerco repressivo e a suspeita sobre os artistas de MPB e seu público eram de tal magnitude que ações corriqueiras foram objeto de descrição detalhada nos "informes". Num deles²2 informa-se que

foram introduzidos nas dependências do COLÉGIO D. PEDRO II, sem qualquer autorização, cartazes alusivos a um show sob o título "Circuito Universitário", 
programado para o dia 13/10/1972 às 21 horas, de Chico Buarque e o conjunto MPB-4, a ser realizado na Faculdade de Humanidades Pedro II, Campo de São Cristóvão, ao preço de 10 cruzeiros.

Em seguida, uma série de informações aparentemente desconexas são enumeradas, referindo-se ao tal show proibido: ${ }^{23}$

tomando ciência de tal fato, o Diretor Geral mandou retirar os referidos cartazes e, incontinenti, baixou a portaria $\mathrm{n}^{\mathrm{0}} 104$, que proibia tal reunião, pelos motivos nela expostos.

Que a aluna $\mathrm{LEDA}^{*}$ era a mais interessada na realização do referido show.

Que a capacidade do Ginásio da FAHUPE II é de 5.000 lugares, não se sabendo a quem se reverteria o lucro que se apurasse.

Neste segundo trecho do documento que, a rigor, não descreve nada de "subversivo", mesmo para os padrões da paranóica direita militar da época, notamos a preocupação em: a) registrar a reação do diretor da faculdade, para verificar uma possível conivência com as atividades estudantis; b) nomear a aluna que estava diretamente envolvida e "interessada" na realização do espetáculo; c) aferir a capacidade de lotação do ginásio, como forma de prever o potencial de público presente num possível espetáculo naquela dependência; d) apontar uma dúvida insidiosa sobre o destino do lucro do espetáculo, sugerindo nas entrelinhas um possível financiamento de "atividades subversivas”. Documentos como esse são verdadeiros paradigmas das estratégias de "produção da suspeita", mesmo quando, a rigor, nada tinham a registrar. Suspeitava-se dos artistas, do diretor da Faculdade, da aluna "interessada", do destino da receita.

Àquela altura, 1972, Chico Buarque era um dos artistas mais vigiados pela censura e pela "comunidade de informações" e qualquer evento que contasse com a sua presença era digno de atenção. Se Chico Buarque já aparecia como um "agente do grupo da MPB" desde os anos 60, o episódio envolvendo a música Apesar de você, em 1970, quando a crítica ao ditador disfarçada em uma querela amorosa acabou sendo liberada pela censura e vendendo cem mil compactos, até ser cassada, piorou o grau de suspeita que recaía sobre suas costas. O Centro de Informações do Exército - CIE registrou as atividades do compositor como se ele fosse a "ponta de um iceberg" do mundo da "subversão". Vale a pena a longa transcrição, que deixa claro o grau de infe- 
rências, conexões improváveis e considerandos que os informes desenvolviam, sem o mínimo compromisso com a verdade: ${ }^{24}$

O cantor nominado, autor de canções de protesto contra a revolução de 1964, e hostil ao nosso governo, vem promovendo seguidas apresentações na área estudantil, com grande receptividade em todas as faculdades onde realizou os seus programas. Artistas como Nara Leão, Capinam, Macalé, Vinícius de Moraes, Gilberto Gil, Sérgio Ricardo, Marília Medalha [sic], Trio Mocotó, MPB-4, Ziraldo, Egberto Gismonti, Luiz Gonzaga Jr., Edu Lobo, Alaíde Costa, Milton Nascimento [todos marcados com sinal que indica citação em outros documentos e prontuários] realizam a mesma programação artística de Chico Buarque, mantendo os estudantes em permanente expectativa política e sob influência de um proselitismo desagregador por eles disseminado durante os espetáculos. Considerando as tendências de esquerda do nominado e desse grupo de artistas, há possibilidade de haver ligação entre as atividades deles na área estudantil e as previsões de agitação conseqüentes das resoluções firmadas em Varsóvia, pelo comitê da União Internacional dos Estudantes, tratados em informação de referência (CIE 24405/103-2, 3/10/72). É conveniente acompanhar e observar estas atividades para neutralizar com oportunidade os efeitos negativos das mesmas, caso sejam constatados indícios de propaganda subversiva ou incitamento à agitação estudantil.

Curioso notar que o anexo ao informe "confidencial" que parece querer desbaratar uma ampla rede de perigosos subversivos era uma pequena matéria da Folha de S. Paulo, de $1^{\circ}$ de outubro de 1972, intitulada "Chico Buarque começa o circuito universitário”, sem nenhuma informação substancial sobre a opinião política do compositor. Não apenas o "circuito universitário" foi vigiado pelos serviços de informação. Mesmo quando um espetáculo estava ligado à grande mídia e não apresentava nenhuma conotação político-ideológica explícita, a lógica da produção da suspeita imperava nos informes. Por ocasião de um espetáculo ao ar livre no campo do Flamengo, no Rio de Janeiro, patrocinado pela insuspeita Rede Globo em 1974, aliada ao regime militar, o relator informa: $:^{25}$

Os participantes do show, em sua maioridade, eram conjuntos vocalistas e instrumentistas, tais como "Os novos baianos", "Zé Rodrix", "Moeda Quebrada", "Os meninos de Deus" (ou Filhos de Deus) e "Achados e Perdidos". O show teve a presença de cerca de 1.500 pessoas, com predominância do tipo "hippie", cer- 
tamente motivado pela propaganda que prometera "um espetáculo do nível de woodstock ao ar livre.

Depois das considerações sociológicas, nas quais os hippies apareciam como um público menos perigoso que os comunistas, mas digno de vigilância, o agente conclui: "Não se registraram incidentes durante o show, que também não teve qualquer conotação política”.

Entretanto, o relator não perde a chance de observar algo de ilegal e anormal em meio à despolitização geral, traduzindo o imaginário que colocava "subversivos" e "maconheiros" na mesma condição de suspeitos:26 "Apenas, segundo os observadores, um pequeno grupo de assistentes fumou maconha abertamente, apesar da presença dos soldados da Polícia Militar, que ignoraram o fato, não obstante alertados”.

Na segunda metade da década de 1970, com a política de "abertura política" já consolidada e com a derrota completa das organizações da esquerda armada, o campo cultural da esquerda continuava sendo vigiado. Mesmo o tom aparentemente objetivo e burocrático em algumas "informações" registrava todas as possíveis portas de entrada da "subversão" no mundo da cultura: ${ }^{27}$

Gente era o título do show de música popular brasileira, promoção do Grupo Sombras e produção da Difusão, apresentando a partir das 21 horas de ontem no ginásio do S. C. Corinthians, à rua São Jorge 777 ... os cantores Chico Buarque de Hollanda, Elis Regina, Francis Hime, Ivan Lins, Luiz Gonzaga Jr., Marcus Vinícius, Sérgio Ricardo, dentre outros, sob a coordenação de Fernando Peixoto e Maurício Tapajós. Na oportunidade, grupo de jovens ali presente tentava angariar assinaturas para o grupo de publicações composto de Brasil Mulher, De Fato, Versus, Coojornal, Posição, O São Paulo.

Os mesmos nomes da MPB eram reiterados como suspeitos, mas passaram a ser relacionados aos espetáculos que saíam das esferas dos campi universitários e ocupavam grandes ginásios esportivos de clubes, parte das campanhas cívicas da oposição, como a campanha por Anistia ou pela volta das liberdades democráticas. A citação ao Grupo SOMBRAS - Sociedade Musical Brasileira, criado em 1974, é interessante, na medida em que esse grupo constituía uma tentativa de organização dos artistas “cidadãos" ligados ao campo da MPB, que se viam lesados nos seus direitos autorais e haviam rompido com a SICAM - Sociedade Independente de Compositores e Autores Musicais, a sociedade arrecadadora dominada pelos músicos anônimos e de 
tendência mais conservadora. ${ }^{28}$ A suspeita podia ser depositada no artista, mas também no público, o "grupo de jovens" que tentava angariar apoio para as publicações da imprensa alternativa de esquerda.

Os eventos musicais ligados ao movimento operário ocupariam os relatórios dos agentes da repressão a partir de 1979. Logo após o frustrado atentado do Riocentro, cuja bomba explodiu no colo do agente do DOI/CODI antes de ser transportada para dentro do galpão, o I Exército sintetizou as atividades "subversivas" do CEBRADE ${ }^{29}$ - Centro Brasil Democrático, procurando incriminá-lo pelo atentado, numa clara produção da suspeita para desviar dos verdadeiros culpados os olhares da própria comunidade de informações, da investigação policial e da justiça.

A informação $0^{30}$ em questão era uma peça de fantasia mal-intencionada, revelando as estratégias de produção de acusações e suspeitas forçadas, sem o mínimo lastro de verdade ou plausibilidade:

1. O show artístico realizado no Riocentro, no último dia 30 de abril, durante o qual agentes do DOI/ I Exército foram vítimas de um atentado terrorista, foi organizado pela sociedade civil denominada CENTRO BRASIL DEMOCRÁTICO (CEBRADE).

2. Criado pela iniciativa de Oscar Niemeyer, Enio Silveira e Sérgio Buarque, que constituíram a primeira diretoria, juntamente com Antônio Houaiss.

O CEBRADE, qualificado de saída como uma organização "terrorista" comandada por intelectuais de prestígio internacional, era vista como uma espécie de organização clandestina e subversiva que articulava o mundo da música popular às organizações sindicais, numa clara alusão às estratégias de alianças de intelectuais e artistas de esquerda com a classe operária. Neste caso, a estratégia sonhada da esquerda se transformava em seu espelho invertido, prova da periculosidade e grau de organização os artistas e intelectuais "subversivos" e "terroristas". Tentando dar plausibilidade à ficção imaginativa da acusação, o documento arrola as atividades do CEBRADE, desde 1979, justamente quando a "questão sindical" se politiza, com a greve de março nas indústrias metalúrgicas do $\mathrm{ABC}$ paulista:

10. No dia 30 de abril de 1979, o CEBRADE realizou no Riocentro um show beneficente de música popular brasileira com renda para o "Encontro Nacional de Líderes Sindicais". O organizador e apresentador foi o compositor Chico Buarque de Holanda; participaram com músicas de mensagens políticas 
e de protesto os seguintes cantores e conjuntos: Maria Bethânia, Clara Nunes, Baby Consuelo, Clementina de Jesus, Cor do Som, Cristina Buarque e Velha Guarda da Portela, Dominguinhos, Edu Lobo, Época de Ouro, Francis Hime, Gal Costa, Gonzaguinha, Ivan Lins, Paulinho da Viola, Martinho da Vila, Moraes Moreira, MPB-4, Peninha, Pepeu Gomes, Rosinha de Valença, Sérgio Ricardo, Simone, Sivuca, Toquinho, Zizi Possi, Ivone Lara e Ziraldo. O tema da concentração foi a anistia ampla, geral e irrestrita.

11. Esse tema seria revivido pouco depois em outra promoção do CEBRADE. Desta vez na sede da ABI, no dia 9/7/1979, em ato dirigido pelo seu presidente BARBOSA LIMA SOBRINHO, contando com a colaboração de Chico Buarque, secretário do CEBRADE e do escritor ANTÔNIO HOUAISS ...

12. Com os recursos obtidos no show de 30 de abril (item 10), estimados em cerca de três milhões e meio de cruzeiros, o CEBRADE patrocinou o I ENCONTRO NACIONAL DE LÍDERES SINDICAIS, realizado no período de 2 a 6 de agosto de1979, no Novotel, em Gragoatá, Niterói.

22. Ao ensejo do Dia do Trabalho, de 1980, o CEBRADE realizou, pela segunda vez, o "Show 1ํ de maio", reunindo grandes nomes da música popular brasileira (roteiro em anexo) e elevado a público $[s i c]$ com renda prevista para ser destinada ao CONCLAT — Congresso Nacional das Classes Trabalhadoras.

Essa "informação" é uma síntese do imaginário anticomunista e antidemocrático da direita militar ligada aos serviços de segurança. Na lógica da repressão, artistas da MPB, CEBRADE, ABI, intelectuais de esquerda, anistia "ampla, geral e irrestrita", Chico Buarque e movimento operário eram parte de uma grande conspiração para desestabilizar o regime e a ordem vigente, através de eventos aparentemente pacíficos. Se esse documento fosse produzido alguns anos antes, poderia dar início a uma onda de perseguição e repressão sem precedentes. Mas, no início da década de 1980, a política de abertura já estava consolidada, com a negociação entre a oposição liberal e o centro decisório das Forças Armadas em estado avançado, visando a volta gradual dos civis ao poder. Mas a "comunidade de informações", neutralizada desde, ao menos, 1976, ainda estava viva e patrocinava atentados contra entidades da sociedade civil, com três finalidades básicas: dificultar o diálogo do regime militar com setores liberais da sociedade civil (base da agenda da "abertura"), criar um clima de radicalização política, entre direita e esquerda e chantagear governo e sociedade para impedir qualquer punição pelas constantes violações aos Direitos Humanos, cometidas principalmente entre 1969 e 1976. O 
"caso Riocentro" foi o canto de cisne da comunidade de informações que, em troca da impunidade, negociava sua desmobilização enquanto força política autônoma dentro do Estado.

\section{A VIGILÂNCIA SOBRE OS ARTISTAS DO MEIO MUSICAL}

Geraldo Vandré se tornou o ícone do artista engajado, perseguido e censurado, ao longo do regime militar brasileiro. Se para a sua carreira esse fardo tornou-se insuportável, levando-o a abandonar a vida artística, ao mesmo tempo o foco que os serviços de informação e repressão jogaram sobre ele contribuiu para que se tornasse uma espécie de lenda viva. A informação que reproduzimos a seguir, ${ }^{31}$ elaborada no auge do sucesso de Vandré, em 1968, é uma mistura de ficha síntese, levantamento biográfico e informe sobre as ligações políticas e sobre as movimentações do artista. A informação começa com um tom aparentemente neutro e objetivo, arrolando os dados civis e profissionais de Vandré:

GERALDO PEREIRA DE ARAÚJO DIAS, pseudônimo de Geraldo Vandré, filho de José Vandrigésilo de Araújo Dias e de Maria Marta de Pedrosa Dias, natural de João Pessoa, Estado da Paraíba, nascido em 12 de setembro de 1935, funcionário efetivo da SUNAB, oriundo da COFAP, como inspetor de indústria e comércio nível 15, identificado sob o número 3254224-SP, residente à Alameda Barros nํㅜㄹ, SP.

A ênfase nos dados profissionais ("fiscal da SUNAB") ganha uma importância estratégica dentro da produção da suspeita, pois um dos argumentos dos militares para perseguir muitos cidadãos era a prevaricação e a corrupção. Ou seja, o fato de Vandré ser artista e funcionário público poderia ser utilizado em futuros processos e investigações. Em seguida, o informante-relator aponta uma outra atividade "cultural", já marcada com o estigma da "subversão":

é membro de um grupo orientado por Martha*, dirigente da editora "O Sol" (Editora Cultural) que se constituía num dos principais meios de ação psicológica sobre o público, desenvolvido por um grupo de cantores e compositores de orientação comunista, atuando em franca atividade nos meios culturais.

A marca da "canção de protesto" também era utilizada como agravante 
do estigma da suspeita e da subversão. Vandré, como acontecerá posteriormente com Chico Buarque, era identificado como uma espécie de líder do "grupo da MPB", afirmação um tanto questionável, quando se conhecem as tensões e debates internos a essa tendência musical. O relator destaca a canção Aroeira, sucesso de 1966, cuja mensagem engajada era mais explícita que em Disparada. Neste sentido, o tom exortativo da canção é arrolado como peça acusatória e prova material "ostensiva” do crime de subversão:

Entre os principais agentes desse grupo, figura Geraldo Vandré. A ação se desenvolve através da chamada "música de protesto", numa propaganda sub-liminar muito bem conduzida. Entre as músicas mais difundidas por aquelas emissoras, destaca-se AROEIRA, de Geraldo Vandré, cujo texto emprega ostensivamente a revolta e a subversão.

Depois de arrolar os dados pessoais e profissionais, sugerir ligações com atividades culturais contestadoras e nomear Vandré como arauto da canção de protesto, o relator do documento culmina na prova maior da subversão: as ligações com grupos de esquerda clandestinos e a viagem a países do bloco soviético:

Geraldo Vandré é tido como comunista atuante. Consta que seu pai, médico em João Pessoa, é um dos chefes comunistas do Estado da Paraíba. Segundo anotações datadas de 13 de agosto de 1968, GV é identificado como pertencente ao movimento determinado "AP" ... encontra-se na Bulgária, onde participou do Festival Mundial da Juventude realizado em Sófia, concorrendo com a apresentação de uma canção denominada "CHE", obtendo o $1^{\circ}$ lugar, sendo-lhe agraciado o grande prêmio medalha de ouro. O cantor em apreço deixou o Brasil no dia 22 de julho último, acompanhado do Trio Maraiá, compondo uma comitiva de 150 pessoas, incluindo intelectuais, estudantes e parlamentares. Consta que atualmente se encontra em Moscou, onde fará uma série de apresentações na TV Russa. Seu regresso está previsto para o dia 30, em São Paulo, vindo de Lisboa. (Informação 093, DOPS/DI, 14/10/1968)

A estratégia textual da produção da suspeita (neste caso, praticamente, da comprovação do crime de subversão) era clara: preencher todas as lacunas com informes obtidos por outras fontes ("consta", "segundo anotações", "é tido como comunista"). A presença no Leste europeu, apresentando odes musicais a Ernesto "Che" Guevara, acompanhado de "intelectuais, estudantes e parlamen- 
tares" e a possível visita a Moscou, não comprovada pelo documento, transformam o inocente "fiscal da SUNAB" no perfil de um "comunista atuante", com ramificações internacionais, ou seja, no grau mais perigoso de subversivo. Pouco importa a origem dos dados. A suspeita estava produzida e pronta para ser acionada pela repressão. No caso de Vandré, ela veio com toda a força.

Um outro caso de suspeita muito peculiar foi o de Caetano Veloso. As posições políticas de Caetano, sempre críticas em relação à arte engajada de esquerda, já conhecidas no final dos anos 60 , acabaram gerando uma série de conflitos entre sua personalidade pública e o público de esquerda, que o qualificava como "alienado". Suas notórias posições políticas independentes e, num certo sentido, distantes da arte engajada, no sentido tradicional da expressão, não foram suficientes para dirimir a suspeita da ditadura. Ao contrário, os órgãos de informação tinham uma especial atenção em relação às suas declarações e performances (mais do que em relação às suas músicas em si). O prontuário de Caetano ${ }^{32}$ arrolava fatos conhecidos, muitos deles extraídos de jornais, mas o fazia como se revelasse um perfil militante e perigoso para o regime. O primeiro ponto, numa demonstração de ignorância da história musical, liga a Bossa Nova à cultura estudantil de esquerda. Neste caso, a participação no espaço e o tipo de show (o teatro Paramount, usado pelas organizações estudantis) era a prova de "esquerdismo":

1. Informação reservada 1-6-65: show teatro Paramount - 18-5-65 "Shows dos chamados 'Bossa Nova', que vêm servindo como campanha de estímulo aos movimentos estudantis de caráter nitidamente esquerdista”.

A participação no "grupo baiano", conforme o agente, era outra prova de "subversão". Mais uma prova do quanto as peças acusatórias não se preocupavam com a veracidade e a qualidade das informações. Para o relator o grupo "vem cantando músicas de protesto subliminarmente atacando o regime vigente e exaltando os regimes socialistas". Mesmo na época, era notório que o "grupo baiano", núcleo do Tropicalismo musical, tinha uma posição de crítica à canção de protesto strictu sensu e não fazia nenhum tipo de exaltação aos regimes socialistas, estando muito mais próximo dos valores da contracultura e das agitações estudantis do Maio de 68 francês.

O informante consegue inventar o "ritmo tropicalista", gênero que nenhum historiador ou musicólogo conseguiu identificar até hoje. Mas o "rit- 
mo tropicalista" surge aqui como mais uma prova de subversão, ao conspurcar o Hino Nacional.

2. Informação reservada 10-10-68: relata as provocações que caracterizam uma ameaça de desmoralização da revolução de 31 de março ... inclusive de que o epigrafado, que se exibia na Guanabara, cantara o Hino Nacional em ritmo tropicalista.

Finalmente, a notícia da intenção de um grupo de fiéis do Senhor do Bonfim em processar o compositor também é arrolada como peça de agravamento da suspeição:

3. Fiéis da ordem da Igreja do Bonfim quiseram processar Caetano pela gravação do Hino do Sr. do Bonfim.

Esse tipo de "prontuário", a rigor, não revelava nada que não tivesse caráter notório e conhecido. A participação nos espetáculos do Paramount, os espetáculos em campi universitários, notícias sobre a prisão após o AI-5, a reação de fiéis conservadores. Enfim, notícias publicadas em jornais eram arroladas como se fossem descobertas inéditas e provas de suspeição, quando na verdade não revelavam nada do que já não fosse conhecido do público que acompanhava a carreira de Caetano. Apenas o episódio do "hino nacional" em ritmo tropicalista, conforme o próprio compositor, havia sido fruto de uma delação feita por Randal Juliano, radialista conservador de São Paulo, que numa versão fantasiosa denunciou as performances durante a temporada na boate Sucata, em outubro de 1968, como subversivas. Nas palavras do próprio Caetano: $:^{33}$ "Randal Juliano resolveu criar uma versão fantasiosa em que nós aparecíamos enrolados na bandeira nacional e cantávamos o Hino Nacional enxertado de palavrões".

Essa denúncia teria servido de argumento para a prisão de Caetano e Gil, por três meses, no final de 1968. A lógica persecutória da repressão servia-se de fatos reais, por vezes banais e conhecidos, mesclando-os com informações fornecidas por delatores profissionais ou espontâneos. Além, é claro, de inferências e livres conclusões elaboradas pelo próprio relator do documento.

A participação em eventos públicos e autorizados, ainda mais quando realizados dentro dos espaços do movimento estudantil, era descrita como uma atividade clandestina e conspirativa. No caso do prontuário de Gilberto 
Gil, sua participação no espetáculo em homenagem a Alexandre Vanucchi Leme, estudante de geologia da USP, morto sob tortura nas dependências do DOI/CODI de São Paulo, era mais um ponto agravante na suspeição. Ainda mais pelo fato de Gil ter voltado do exílio em Londres pouco tempo antes:

28/3/73 - Show no Anfiteatro do Biênio - Grêmio Politécnico da USP — 1.500 universitários. No final cantou "Cálice", música proibida oficialmente. Boletim informativo do Grêmio Politécnico. "Estando entre os participantes dos festivais dos anos 60" e "artista ligado a Chico Buarque de Hollanda".

A interpretação de Cálice, feita em parceria com Chico Buarque, já proibida pela censura, aliada aos fatos notórios de que participara dos festivais dos anos 60 e era ligado a Chico Buarque de Hollanda, surge como peça acusatória. A rigor, essas informações não necessitariam de nenhum serviço de espionagem, na medida em que eram públicas. Mas dentro da lógica dos textos produzidos pelos serviços de informação eram travestidas de revelação grave e solene, valorizando não apenas a suspeição sobre o vigiado, mas também a ação pretensamente perspicaz dos serviços de inteligência.

Ao pesquisarmos as fichas do DOPS por nomes de compositores e cantores, percebemos que os documentos produzidos pelos agentes mapeiam as suas aparições públicas em shows e eventos ligados aos movimentos sociais, sem se preocupar com o conteúdo das obras (foco da ação da censura). Portanto, a suspeita era produzida pela circulação social do artista em si, para além do conteúdo da sua obra. Elis Regina, por exemplo, é citada pela sua participação nos shows na Campanha da Anistia (PUC, 14/8/79; Parque São Jorge, 17/8/79), em apoio ao movimento operário ( $\mathrm{ABC}, 3 / 4 / 79$, durante a segunda grande greve metalúrgica), e em espetáculos estudantis (show "Gente", 12/77, shows na USP, 10/8/79 e 17/8/79). Milton Nascimento é citado por suas participações em festivais de MPB nos anos 60 (Informe de 4/77), pela sua participação na "semana de liberdades democráticas", pela sua presença na Reunião Anual da SBPC — Sociedade Brasileira para o Progresso da Ciência, em 1976 e 1977. Ivan Lins é citado várias vezes, principalmente a partir de 1977, pela participação em espetáculos estudantis e pela presença nas reuniões da SBPC. Nota-se uma tática dos informantes para estabelecer relações e ligações entre os artistas e os movimentos sociais "subversivos". A reiteração das anotações poderia induzir a futuras conclusões mais comprometedoras para os citados, de acordo com a lógica da repressão, quando seus nomes pode- 
riam ser arrolados como organicamente ligados a grupos clandestinos. Esta, talvez, fosse a acusação mais grave, conforme a escala de suspeição, podendo conduzir à prisão.

No informe produzido pelo DOPS em 1975, ${ }^{34}$ aparece uma lista de artistas que seriam da "base" do Partido Comunista Brasileiro. Mantida a ordem de citação na fonte, seriam os seguintes: Vinícius de Moraes, Toquinho, MPB4, Chico Buarque, Edu da Gaita, Mário Lago, Gilberto Gil, Paulinho da Viola, Jorge Goulart, Nora Ney, Nelson Cavaquinho, Alfredo Dias Gomes, Janete Clair, Ivani Ribeiro, Dionísio Azevedo, Carlos Verezza, Jararaca, Rafael Carvalho e Caetano Veloso.

O informe conclui: $:^{35}$ "Todos os artistas acima participaram de shows organizados pelo PCB com a finalidade de angariar fundos para a seção de finanças, sem nada cobrar pelo seu trabalho".

A participação em "shows organizados pelo PCB", o que em si era uma inferência, na medida em que as produções dos espetáculos de MPB jamais tinham ligação direta com algum partido ou grupo (ainda mais os clandestinos) serve de argumento para listar a pretensa "base de artistas”. Nessa lista, são mesclados nomes de comunistas históricos e assumidos (Mário Lago, Jorge Goulart, Nora Ney, Dias Gomes, Carlos Verezza), artistas engajados com algumas afinidades, mas sem ligação orgânica com o Partido (Chico Buarque, MPB-4, Vinícius de Moraes), artistas populares admirados pelos comunistas (Nelson Cavaquinho) e até críticos da cultura política e da estética do PCB (Caetano Veloso). A total falta de critérios e veracidade colocava todos no mesmo grau de ligação partidária, como se tivessem uma relação orgânica e ativista dentro do Partido. A lista assume uma gravidade ainda maior quando sabemos que, em 1975, os serviços de informação e repressão armavam um cerco ao PCB, até então relativamente poupado da repressão mais violenta por não aderir à luta armada. Ao longo daquele ano, dezenas de militantes e simpatizantes do Partido seriam levados ao DOPS e ao DOI/CODI, e muitos deles morreriam sob torturas.

Voltando à pergunta que abre este artigo: para quem escreviam os espiões do regime militar? Tendo em vista a lógica persecutória auto-referenciada, a falta de veracidade e plausibilidade de muitos informes, o excesso de inferências sem argumentação sólida e de expressões vagas ("consta que..."), poderíamos dizer que os serviços de informação e repressão, acima de tudo, 
escreviam para si mesmos. Entretanto, numa época de autoritarismo, o que poderia ser uma zelosa idiossincrasia policialesca transformava-se em justificativa para ações repressivas sistemáticas e violentas, devidamente acobertadas pelo Estado e pelos poderes constituídos.

Os artistas da MPB, alvos da produção da suspeita, surgem nesses documentos da repressão como arautos de uma conspiração revolucionária que, na maioria das vezes, nascia e morria nas reuniões boêmias, nas conversas a portas fechadas, nos espetáculos que mantinham a "boa palavra" em circulação. O que talvez não fosse pouco em tempos de autoritarismo e silêncio.

\section{NOTAS}

${ }^{1}$ A Delegacia de Ordem Política e Social, no caso de São Paulo, foi criada em 1924 e extinta em 1983. No geral, as várias DOPS estaduais foram criadas na década de 1920 e extintas ao longo da década de 80. Durante o regime militar a DOPS era apenas uma das instituições ligadas à "comunidade de informações", que era composta por inúmeros serviços de espionagem e repressão política, tais como os serviços de informação das três armas (CENIMAR, CIE, CISA), as Divisões e Assessorias de Segurança Interna dos órgãos públicos, a Polícia Federal, as chamadas "segundas seções" das polícias militares e das forças de segurança e o Serviço Nacional de Informações — SNI. Com a criação do sistema CODI/DOI — Centro de Operações de Defesa Interna / Destacamentos de Operações de Informações, em 1970, os agentes desses vários órgãos foram submetidos ao comando unificado do Exército.

${ }^{2}$ FICO, Carlos. Como eles agiam. Os subterrâneos da Ditadura Militar: espionagem e polícia política. Rio de Janeiro: Record, 2001, p.37.

${ }^{3}$ MAGALHÃES, Marionilde B. A lógica da suspeição: sobre os aparelhos repressivos à época da ditadura militar no Brasil. Revista Brasileira de História, v.17, n.34, p.203-20, 1997.

${ }^{4}$ Apud MAGALHÃES, op. cit., p.211.

${ }^{5}$ Boletim Reservado, Seção de Buscas/DOPS, 27/3/74, Fonte: APERJ.

${ }^{6}$ FICO, C. op. cit., p.95.

${ }^{7}$ Ibidem, p.98-9.

${ }^{8}$ Ibidem, p.99.

${ }^{9}$ SSP/RJ. Informe Reservado, 8/1/1968, Fonte: APERJ.

${ }^{10} \mathrm{O}$ circuito universitário vigorou, aproximadamente, entre 1971 e 1975, tendo como um dos seus principais nomes Benil Santos. 
${ }^{11}$ A Campanha da Anistia, coordenada pelo Comitê Brasileiro de Anistia, ganha o espaço público a partir do final de 1978, com a realização do Congresso do CBA. Até agosto de 1979, quando é promulgada a Lei de Anistia, a campanha ganha as ruas das principais cidades brasileiras.

${ }^{12}$ A chamada "questão operária” explode em 1978, quando o movimento operário metalúrgico do ABC paulista realiza a grande greve de maio. Até 1980 foram realizadas três grandes greves operárias, apresentando um grau de politização crescente, aglutinando toda a oposição civil ao regime em torno do movimento.

${ }^{13}$ Utilizamos a expressão para diferenciar essa relação daquela travada entre os movimentos sociais e a música popular a partir de um tipo de experiência midiatizada. Ver EYERMAN, R. \& JAMISON, A. Social movement and cultural transformation. Media, culture and society. London: Sage, v.17, n.3, p.449-68, July 1995.

${ }^{14}$ DOPS/GB 3/8/73, Fonte: APERJ.

${ }^{15}$ Informação 419/1169, II Exército, 23/8/67, Fonte: APERJ.

${ }^{16}$ Ibidem.

${ }^{17}$ DPF-SDR-RJ / CENIMAR 32/DPS/RS, 2/2/72.

${ }^{18}$ Ibidem.

${ }^{19}$ Informação 522/72 H, DO/DOPS, 13/3/72, Fonte: APERJ.

${ }^{20}$ O show em questão foi intitulado "Encontro", de 24/5/72, produzido por Benil Santos no ginásio de esportes de São Carlos. Benil Santos foi o empresário que lançou a idéia de "circuito universitário da MPB", que permitiu aos artistas dessa tendência um contato direto com o seu nicho de público mais fiel, a custo baixo. As cidades médias do interior do Sudeste e do Sul, além das capitais fora do eixo Rio-São Paulo foram abarcadas pelo circuito que durou até, aproximadamente, 1975, quando os principais artistas começaram a preferir shows mais bem produzidos e voltados para um público mais amplo.

${ }^{21}$ Informe 140/72 - 14/8/72.

${ }^{22}$ DSI/DOPS reproduzido da ARSI/GB, Informe 5928 de 4/7/72, Fonte: APERJ.

${ }^{23}$ Ibidem.

${ }^{24}$ Informe "Confidencial” — RJ, 11/10/72, CIE.

${ }^{25}$ Boletim Reservado, 14, DI/DOPS 7359/74, 16/9/74, Fonte APERJ.

${ }^{26}$ Ibidem.

${ }^{27}$ Informação 1555/B-77, 13/12/77.

${ }^{28}$ Sobre esse conflito de sociedades de direito de autor, ver MORELLI, Rita. Arrogantes, 
anônimos e subversivos. Interpretando o acordo e a discórdia na tradição autoral brasileira. Campinas: Mercado de Letras, 2000.

${ }^{29}$ O CEBRADE foi fundado em 1978, presidido por Oscar Niemeyer, e procurava aglutinar uma espécie de Frente Ampla dos intelectuais pela redemocratização, sob inspiração do Partido Comunista.

${ }^{30}$ Informação 3285/81, 15/5/81, I Exército, Fonte: APERJ.

${ }^{31}$ Informação 93, DOPS/DI, 14/10/68.

${ }^{32}$ DI DOPS-SP, 3/11/73.

${ }^{33}$ VELOSO, Caetano. Verdade Tropical. São Paulo: Companhia das Letras, 1997, p.396.

${ }^{34} \mathrm{PCB} /$ Informe DOPS n.6, mar./75.

${ }^{35}$ Ibidem. 